\title{
Increased Mortality of Kainic Acid by Pretreatment with Nicardipine, a Calcium Channel Blocker in Rats
}

\author{
By Tomoko FUJII and Takaro OHATA \\ Department of Pharmacology, Teikyo University School of Medicine, Itabashi, Tokyo 173 \\ (Communicated by Setsuro EBASHI, M. J. A., Feb. 12, 1997)
}

\begin{abstract}
Ca}^{2+}$ channel blockers from two different chemical classes, nifedipine and varapamil, were compared in rats for their ability to inhibit the wet-dog shakes behavior and limbic seizures induced by kainic acid which binds to a subtype of glutamate receptors in the brain. Pretreatment for 30 minutes with nicardipine or verapamil suppressed slightly kainic acid-induced wet-dog shakes independent of the dose $1-4 \mathrm{mg} / \mathrm{kg}$. In the rats treated with $5 \mathrm{mg} / \mathrm{kg}$ of nicardipine or verapamil, however, the frequency of wet-dog shakes decreased to 50-60\% of controls. In contrast, nicardipine accelerated the onset time and frequency of limbic seizures, resulting in increased mortality by kainic acid in the dose-dependent manner. Occurrence of limbic seizures in verapamil-treated rats was similar to that in the controls and the mortality in this group was smaller than in the nicardipine-treated group. Pretreatment with diazepam alone prevented the kainic acid-induced limbic seizures. However, in the rats pretreated with diazepam and nicardipine simultaneously, anticonvulsive effect of diazepam was not shown and the mortality in this group was the similar to that in the nicardipine pretreated group. Both nicardipine and verapamil did not enhance the picrotoxin-induced convulsions. The mechanism of the apparent enhancement of the mortality of kainic acid by even low doses of nicardipine is not clear. This might be, at least in part, correlated with their different mechanism of channel blocking action.
\end{abstract}

Key words : Calcium channel blockers; nifedipine; verapamil; kainic acid; mortality; rat.

Nifedipine, a member of the dihydropyridine group of calcium channel blockers, has been widely used for the treatment of vasospastic and chronic stable angina. In addition, it has been proven efficacious in the treatment of essential hypertension, acute hypertensive crises, achalasia, diffuse esophageal spasm and Raynaud' syndrome. Nifedipine and other currently marketed calcium channel blocking agents, verapamil and diltiazem relax vascular smooth muscle through their ability to block voltage dependent or 'slow' calcium channels. On the other hand, the incidence and scope of nifedipine's side effects has been recently recognized as of much greater than those of verapamil and diltiazem, ${ }^{1-4)}$ suggesting that something in addition to slow calcium channel blockade may be involved in the action of nifedipine.

Clinical experience with the side effect of nifedipine has shown that it may induce myocardial ischemia in patients with refractory angina pectoris, an effect opposite to that expected from calcium channel blockade. Furberg et al. ${ }^{5}$ ) assessed the effect of the dose of nifedipine on the increased risk of mortality seen in the randomized secondary-preventing trials and made a conclusion that in patients with coronary disease, the use of short-acting nifedipine in moderate to high doses causes an increase in total mortality. Other calcium channel blockers may have similar adverse effects, in particular those of the dihydropyridine type. He used the first meta-analysis of clinical trials of calcium channel blockers in myocardial infarction and unstable angina reported all-cause mortality and initial or recurrent infarction among 19,000 patients in 28 randomized trials. ${ }^{6)}$

In the present experiment, we studied the preventive effect of two calcium channel blockers with different chemical structure, nicardipine and verapamil, on the kainic acid-induced limbic seizures in rats. Kainic acid, a neurotoxin, binds to a subtype of glutamate receptors in the brain and results in neural cell death particularly in the hippocampal region due to the increased influx of calcium. ${ }^{7)}$ An excess of free intracellular calcium-ions may become highly toxic for 
various cells including nervous tissues in the brain. ${ }^{8), 9)}$ We report here that pretreatment with nicardipine did not prevent kainic acid-induced limbic seizures but increased its mortality in rats.

Materials and methods. Wistar-Imamichi adult male rats (Institute for Animal Reproduction, Ibaragi) were used. The rats were kept in an air conditioned room with a lighting schedule of $14 \mathrm{hr}$ light and $10 \mathrm{hr}$ darkness (06:00-20:00). They were supplied with a commercial stock diet and tap water ad libitum. They were divided into 3 groups, saline-treated control, nicardipine- and verapamil-treated groups. Nicardipine (Perdipine ${ }^{\circledR i n j, ~ Y a m a n o u c h i ~ P h a r m a c e u t i c a l ~ C o ., ~}$ Ltd. Tokyo) and verapamil (Vasolan ${ }^{\circledR i n j ., ~ E i s a i ~ C o ., ~}$ Ltd. Tokyo) were given with a dose each of $1,3,4$ or 5 $\mathrm{mg} / \mathrm{kg}$ subcutaneously. Control rats received the same volume of saline solution. Thirty minutes after administration of calcium channel blockers or saline, rats were injected intraperitoneally with $9 \mathrm{mg} / \mathrm{kg}$ kainic acid. Kainic acid was dissolved in deionized water and $\mathrm{pH}$ was adjusted to 7.0 with sodium hydroxide solution. Approximately 20 minutes after the treatment with kainic acid, rats started to show wet-dog shakes and followed by limbic seizures 50-60 minutes later. Frequency of wet-dog shakes was counted every 10 minutes for 60 minutes after kainic acid injection, and the time of onset of limbic seizure and its frequency were recorded. Finally mortality in $24 \mathrm{hrs}$ was assessed.

In the second series of experiments, effects of 1 $\mathrm{mg} / \mathrm{kg}$ diazepam (Cercine ${ }^{\circledR}$, Takeda Yakuhin Co., Ltd, Osaka) on the kainic acid-induced wet-dog shakes, seizures and mortality were compared with those obtained in the first series experiments. In addition, the presence of anticonvulsive effect of nicardipine and verapamil on the picrotoxin-induced convulsion was assessed. Picrotoxin (Sigma) was dissolved in deionized water and $3 \mathrm{mg} / \mathrm{kg}$ was injected subcutaneously.

Results. Treatment with a single dose of $9 \mathrm{mg} / \mathrm{kg}$ kainic acid induced scratching of the neck with hind leg within 10 minutes and followed by wet-dog shakes after 10-20 minutes. Frequency of the wet-dog shakes increased time dependently until 50-60 minutes following the injection of kainic acid in saline-pretreated control rats. Frequency of kainic acid-induced wet-dog shakes showed a tendency to decrease when 1,3 or 4 $\mathrm{mg} / \mathrm{kg}$ nicardipine or verapamil was injected $30 \mathrm{mi}$ nutes prior to kainic acid (Figs. 1, 2): the decrease in the frequency of wet-dog shakes was not dosedependent. Only $5 \mathrm{mg} / \mathrm{kg}$ nicardipine or verapamil

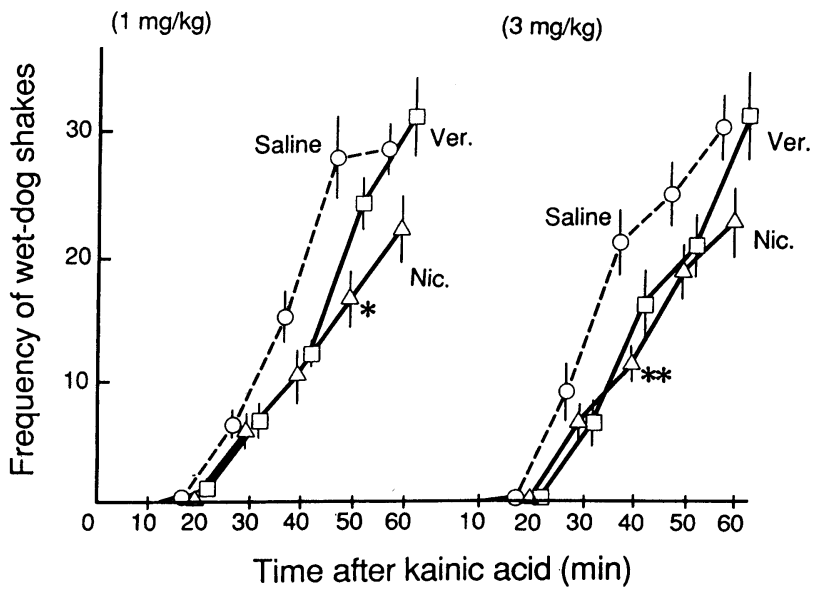

Fig. 1. Effects of pretreatment of nicardipine or verapamil on the frequency of kainic acid-induced wet-dog shakes in 8-week-old male rats. Vertical bars represent the mean+S.E.M. of 12 rats. *, $\mathrm{P}<0.05$; **, $\mathrm{P}<0.01$ vs. saline controls.

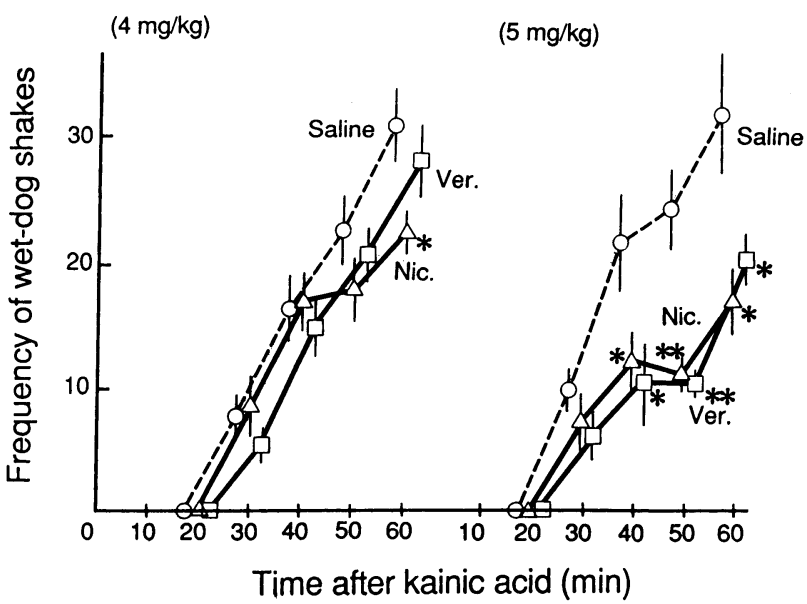

Fig. 2. Effects of pretreatment of nicardipine or verapamil on the frequency of kainic acid-induced wet-dog shakes in 8-week-old male rats. Vertical bars represent the mean + S.E.M. of $12-13$ rats for $4 \mathrm{mg} / \mathrm{kg}$ group and of 7 rats for $5 \mathrm{mg} / \mathrm{kg}$ group. ${ }^{*}, \mathrm{P}<0.05$; **, $\mathrm{P}<0.01$ vs. saline controls.

showed a marked inhibition of wet-dog shakes (Fig. 2). Duration of the suppressive effect of $1-4 \mathrm{mg} / \mathrm{kg}$ verapamil was slightly shorter than nicardipine in the same doses (Figs. 1, 2).

In the nicardipine-pretreated rats, incidence of limbic seizures was higher than that in the salinetreated controls except the group treated with $1 \mathrm{mg} / \mathrm{kg}$ nicardipine and the incidence increased dosedependently, whereas the incidence of limbic seizures in the verapamil-treated rats was nearly equivalent to 
Table I. Effects of 30 minutes-priming of calcium channel blockers on the incidence of kainic acid-induced limbic seizures and its mortality in 8-week-old male rats

\begin{tabular}{|c|c|c|c|c|c|}
\hline \multirow{2}{*}{\multicolumn{2}{|c|}{ Group }} & \multirow{2}{*}{\multicolumn{2}{|c|}{ No. of rats }} & \multirow{2}{*}{\multicolumn{2}{|c|}{ No. of rats }} \\
\hline & & & & & \\
\hline \multicolumn{2}{|c|}{ Saline } & $22 / 42^{\mathrm{b}}$ & 52.3 & $6 / 42$ & 14.3 \\
\hline \multirow[t]{4}{*}{ Nicardipine } & $1 \mathrm{mg} / \mathrm{kg}$ & $4 / 12$ & 33.3 & $4 / 12$ & 33.3 \\
\hline & 3 & $9 / 13$ & 69.2 & $8 / 13$ & 61.5 \\
\hline & 4 & $11 / 14$ & 78.6 & $7 / 14$ & 50.0 \\
\hline & 5 & $2 / 7$ & 28.5 & $7 / 7$ & 100.0 \\
\hline \multirow[t]{4}{*}{ Verapamil } & $1 \mathrm{mg} / \mathrm{kg}$ & $6 / 12$ & 50.0 & $2 / 12$ & 16.7 \\
\hline & 3 & $7 / 12$ & 58.3 & $4 / 12$ & 33.3 \\
\hline & 4 & $6 / 13$ & 46.2 & $2 / 13$ & 15.4 \\
\hline & 5 & $0 / 7$ & 0.0 & $6 / 7$ & 85.7 \\
\hline
\end{tabular}

a, Mean \pm S.E.M.; b, The experiment was carried out with 3 groups each with saline, nicardipine and verapamil in a same dose, Therefore the number of control rats, 42 , is sum of 7 experimental groups.

the controls (Table I). Rats treated with $5 \mathrm{mg} / \mathrm{kg}$ nicardipine or verapamil showed a marked decrease in the limbic seizures (Table I). Continuation and magnitude of seizures in the nicardipine-treated rats were greater than those in saline- and verapamil-treated groups.

Although kainic acid treatment in the salineprimed rats induced limbic seizures in over $50 \%$ of the animals tested, their mortality in 24 hours was $14.3 \%$ (Table I). In contrast, the mortality in the rats pretreated with nicardipine was much higher than that the saline- and verapamil-primed rats (Table I). Mortality in the rats given $5 \mathrm{mg} / \mathrm{kg}$ of nicardipine or verapamil was $100 \%$ and $85.7 \%$, respectively.

Diazepam in a dose which has only weak suppressing effect on the kainic acid-induced wet-dog shakes inhibited completely kainic acid-induced limbic seizures (Fig. 3). When diazepam was given simultaneously with nicardipine, anticonvulsive effect of diazepam was not shown, and $86 \%$ mortality was seen following delayed convulsions (Fig. 3). In order to characterize the enhancing effects on the response to kainic acid, nicardipine and verapamil were injected prior to injection of picrotoxin. The onset time of the first convulsion and frequency of tonic-clonic convulsion did not differ significantly between saline-treated and calcium channel blocker-treated groups, though verapamil slightly suppressed the convulsive effect of picrotoxin (Table II).

Discussion. After the development of calcium channel blockers as therapeutic drugs for the ischemic

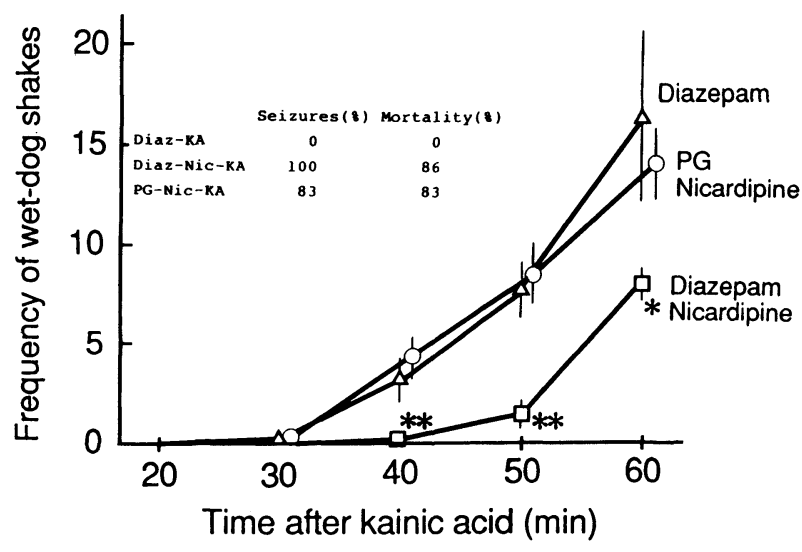

Fig. 3. Effects of pretreatment with diazepam or nicardipine alone or diazepam with nicardipine on the kainic acid-induced wet-dog shakes, incidence of limbic seizures and mortality in 8-week-old male rats. Vertical bars represent the mean+S.E.M. of $6-7$ rats. ${ }^{*}, \mathrm{P}<0.05$; $* *, \mathrm{P}<0.01$ vs. nicardipine-treated group.

Table II. Effect of the 30-min priming of Ca channel blockers on the picrotoxin ( $3 \mathrm{mg} / \mathrm{kg} \mathrm{sc}$ )-induced seizures

\begin{tabular}{lccc}
\hline & $\mathrm{n}$ & $\begin{array}{c}\text { Onset time } \\
(\mathrm{min})\end{array}$ & $\begin{array}{c}\text { Frequency of tonic-clonic } \\
\text { convulsion }\end{array}$ \\
\hline Saline & 6 & $20.9 \pm 1.1^{*}$ & $2.0 \pm 0.4$ \\
Nicardipine & 6 & $21.1 \pm 1.0$ & $2.7 \pm 0.6$ \\
Verapamil & 6 & $26.3 \pm 4.6$ & $1.7 \pm 0.2$ \\
\hline
\end{tabular}

* Mean士S.E.M. 
heart disease or hypertention, there have been numerous reports indicating preventive action of calcium channel blockers on the glutamate or high-potasiuminduced $^{10)}$ or N-methyl-D-aspartate (NMDA)evoked $^{11)}$ calcium influx into neural cells in the brain. Pauwels $e t a l{ }^{12)}$ also indicated that flunaridine protects neural cell death induced by a decrease in $\mathrm{Na}^{+}$ influx may prevent cytotoxicity secondary. However, Dolin et $a l .{ }^{13)}$ have found that dihydropyridines, nitrendipine and nimodipine, cause small but significant increase in the severity of seizures produced by NMDA and that these two calcium channel blockers antagonized pentylenetetrazol-induced convulsion. There are many differences between the major three classes of calcium channel blockers and their derivatives at chemical, experimental and clinical level. The major difference between the individual calcium channel blockers relates to their calcium antagonistic selectivity, tissue specificity and duration of action. These different properties as calcium channel blockers might be related to the present finding. We assume that the cause of death by nicardipine is not due to its suppressing action of cardiac function because of that verapamil is much more selective to cardiac tissues as compared with that of nicardipine and contrary nicardipine and nifedipine have been reported to bind selectively to calcium channels of the smooth muscle of the vessel. We also have experiences in animal experiments that a rapid intravenous injection of verapamil at the dose over $3 \mathrm{mg} / \mathrm{kg}$ induces the respiratory arrest as well as cardiac arrest in a short period of time though it is reversible in a seconds, but nicardipine does not show these effects.

Rat hippocampal neurons are extremely sensitive to the neurotoxic action of the potent convulsant, kainic acid. Kainic acid is a naturally occurring cyclic analogue of glutamate. Commonly used calcium channel blockers, nifedipine, verapamil, and diltiazem, penetrate the blood-brain barrier and bind to specific binding sites in many brain areas. ${ }^{14)}$ Receptor binding sites for 1,4-dihydropyridine (DHP) calcium blockers have been characterized by using $\left[{ }^{3} \mathrm{H}\right]$-nimodipine, a potent analogue of nifedipine and showed binding with specific membrane-located receptor sites. ${ }^{15)}$ Mikami et $a l .{ }^{16)}$ noted that dihydropyridine calcium antagonist binding sites of L-type calcium channel in the membrane of skeletal muscle is $\alpha_{1}$ subunit. As L-type channel blockers, it appears that nicardipine blocks the outside the membrane but Janis and Scriabine ${ }^{17)}$ reported that verapamil may act on the inside of cardiac membranes after entering the cell in the unchanged form.

In the present results, enhancing activity of the death by kainic acid is greater in nicardipine than verapamil. The potency of channel blocking has been compared by several investigators. The inhibitory effects of dihydropridine derivatives, nifedipine and phenylalkylamines, verapamil were compared by Hagiwara et al. ${ }^{18)}$ and they found that maximal inhibition was obtained with $100 \mathrm{nM}$ nifedipine and 10 $\mu \mathrm{M}$ verapamil in the vascular muscle of rat. Shrivastava et $a l .{ }^{19)}$ used hepatotoxicity to classify several calcium blockers. Nifedipine and verapamil are in the same group in their range of hepatotoxicity for the compounds, and diltiazem is less toxic as evaluated by hepatotoxicity. Most strong toxic agents were flunarizine, fendiline and cinnarizine.

The mechanisms of enhancing action of the response to kainic acid is unknown. However, there are several reports showing that typical three calcium channel blockers possess various additional biochemical characters. Phillis et $a l .{ }^{20)}$ found that nifedipine, a dihydropyridine derivatives, inhibits the uptake of adnosine dose-dependently by rat brain cortical synaptosomes. Swanson and Green ${ }^{21)}$ found that nifedipine inhibits a bidirectional "tranporter" system for adenosine, and in this manner, may alter the action of endogenously released adenosine. They also found that both nifedipine and adenosine interact with benzodiazepine binding sites. Moreover, intracellularly, dihydropyridine calcium antagonists bind to calmodulin to inhibit calmodulin-mediated events. ${ }^{22)}$ Above mentioned biochemical characters are not only of dihydropyridine derivatives, but also verapamil has been suggested to interact with the same receptor of benzodiazepines. ${ }^{23)}$ In the present results, it is clearly shown that nicardipine antagonized anticonvulsant effect of diazepam when injected a few minutes before the injection of nicardipine, while $1 \mathrm{mg} / \mathrm{kg}$ diazepam alone completely inhibited kainic acid-induced limbic seizures. This suggests that nicardipine binds at the same sites in the brain, at least in part, with benzodiazepines as stated by others. As reported by Glossmann et al. ${ }^{24)}$ structurally different but similarly inhibiting L-type calcium currents might act at allosterically linked sites. 


\section{References}

1) Bosso, J. V., Gazzara, P. C., and Rosati, M. (1986) New. Engl. J. Med. 315, 584.

2) Gaudron, P., Blumrich, M., and Ertl, G. (1993) Am. Heart J. 125, 1226-1232.

3) Fukuuchi, Y. (1992) Jpn. Med. J. no. 3552, pp. 3-13.

4) Steiner, G., and Pauly, N. C. (1994) J. Cardiovasc. Pharmacol. 23 (Suppl. 4), S81-S85.

5) Furberg, C. D., Psaty, B. M., and Meyer, J. V. (1995) Circulation 92, 1326-1331.

6) Held, P. H., Yusuf, S., and Furberg, C. D. (1989) Br. Med. J. 299, 1187-1192.

7) Bickler, P. E., and Hansen, B. M. (1994) Brain Res. 665, 269-276.

8) Silver, I. A., and Erecinska, M. (1990) J. Gen. Physiol. 95, $837-866$.

9) Dubinsky, J. M., and Rothman, S. M. (1991) J. Neurosci. 11, 2545-2551.

10) Zhang, X.-Q., Watanabe, Y., Ohnishi, M., Baba, T., and Shibuya, T. (1993) Jpn. J. Pharmacol. 62, 411-414.

11) Skeen, G. A., White, H. S., and Twyman, R. E. (1994) J. Pharmac. Exp. Therap. 271, 30-38.

12) Pauwels, P. J., Leysen, J. E., and Janssen, A. J. (1991) Life Sci. 48, 1881-1893.

13) Dolin, S. J., Hunter, A. B., Halsey, M. J., and Little, H. J.
(1988) Eur. J. Pharmacol. 152, 19-27.

14) Snyders, S., and Reynolds, I. (1985) New Engl. J. Med. 313, 995-1002.

15) Bellemann, P., Achade, A., and Towart, R. (1983) Proc. Natl. Acad. Sci. 80, 2356-2360.

16) Mikami, A., Imoto, K., Tanabe, T., Niidome, T., Mori, Y., Takeshima, H., Narumiya, S., and Numa, S. (1989) Nature 340, 230-233.

17) Janis, R. A., and Scriabine, A. (1983) Bioch. Pharmacol. 32, 3499-3507.

18) Hagiwara, S., Mitsui, M., and Karaki, H. (1993) Eur. J. Pharmacol. 234, 1-7.

19) Shrivastava, R., John, G., and Massingham, R. (1992) J. Appl. Toxicol. 12, 329-332.

20) Phillis, J. W., Swanson, T. H., and Barraco, R. A. (1984) Neurochem. Int. 6, 693-699.

21) Swanson, T. H., and Green, C. L. (1986) Gen. Pharmacol. 17, 255-260.

22) Johnson, J. D., and Fugman, D. A. (1983) J. Pharmac. Exp. Therap. 226, 330-334.

23) Murphy, K. M. M., Gould, R. J., Largent, B. L., and Snyder, S. H. (1983) Proc. Natl. Acad. Sci. U.S.A. 80, 860-864.

24) Glossmann, H., Ferry, D. R., Goll, A., Striessnig, J., and Schober, M. (1985) J. Cardiovasc. Pharmacol. 7 (Suppl. 6), S20-S30. 